\title{
Dose-response study of inhaled salbutamol powder in chronic airflow obstruction
}

\author{
PA CORRIS, E NEVILLE, S NARIMAN, GJ GIBSON \\ From the Regional Cardiothoracic Centre, Freeman Hospital, Newcastle upon Tyne
}

ABSTRACT Dose-response relationships for salbutamol were studied in eight patients suffering $\underset{\infty}{\omega_{\infty}}$ from chronic airflow obstruction with no asthmatic features. Each inhaled, double blind, in ${ }_{\perp}$ randomised order $0,200,400,800$, and $1600 \mu \mathrm{g}$ salbutamol on five successive mornings. Before $\tilde{C}_{0}$ and at intervals up to six hours after the inhalation $\mathrm{FEV}_{1}$, vital capacity, maximum inspiratory ${ }_{0}^{\mathrm{N}}$ and expiratory flow-volume curves, and 12-minute walking distances were measured. Analysis of $\stackrel{\circ}{\supset}$ variance of the results indicated significant dose-response relationships and showed the larger $\vec{\nabla}$ doses to have a longer duration of action. Simple spirometric tests were as useful in providing 으․ objective evidence of benefit as maximum inspiratory flows or the 12-minute walking distance.

Salbutamol is frequently prescribed as an inhaled preparation for patients with chronic airflow obstruction in a dose of 200 or $400 \mu \mathrm{g}$ four times a day. The successful use of much larger doses of nebulised respirator solution in patients with asthma ${ }^{12}$ has led to similar treatment in patients with chronic airflow obstruction. Many appear to show a greater improvement on these higher doses (5 or $10 \mathrm{mg}$ ) but it is not clear whether this is related to the dose or to the means of administration. There is some evidence that tests of forced expiration alone, such as $\mathrm{FEV}_{1}$, may not be the most useful for monitoring improvement in such patients because of the effects of dynamic airway compression. ${ }^{3}$ The relaxed vital capacity (VC), ${ }^{4}$ 12-minute walking distance (12$\mathrm{MD}),{ }^{5}$ and maximal inspiratory flow at $50 \%$ of $\mathrm{VC}^{6}$ have all been suggested as alternatives. We have carried out a dose-response study of inhaled salbutamol powder in patients with chronic airflow obstruction and used these indices in addition to spirometric measurements.

\section{Methods}

Eight patients with stable chronic airflow obstruction were studied. Their ages and the results of spirometry and of measurements of lung volumes, transfer factor, and transfer coefficient $(\mathrm{KCO})$ are

Address for correspondence: Dr PA Corris, Regional Cardiothoracic Centre, Freeman Hospital, Newcastle upon Tyne NE7 7DN. Reprints will not be available.

Accepted 24 November 1982 shown in the table. All had been cigarette smokers and were considerably disabled by breathlessness. Care was taken to exclude patients with asthmatic features from the study by the following criteria foro entry: (1) improvement of $\mathrm{FEV}_{1}$ not greater than ${ }_{\Omega}^{\Phi}$ $15 \% 15$ minutes after two puffs of salbutamol; $(2)$ no response to a steroid trial, defined as failure of 3 the $\mathrm{FEV}_{1}$ to rise by $15 \%$ after $30 \mathrm{mg}$ prednisolone? for two weeks; (3) no blood eosinophilia; (4) noo sputum eosinophilia; (5) negative responses to skin tests for common allergens.

No patient was studied within one month of $a_{x}$ respiratory tract infection. All patients were using ao $\beta$-agonist inhaler regularly and none was taking? either inhaled or oral corticosteroids before theo study. Each patient was asked not to use $\beta$-agonists $\beta$ during the 10 days preceding the study, to minimiseo any effects of tolerance to salbutamol. ${ }^{7}$ Oral $_{\supset}$ theophylline or an anticholinergic inhaler (or both

Results of spirometry and measurements of lung volumes, transfer factor (TLCO) and transfer coefficient (KCO) in the eight patients (all values expressed as \% predicted)

\begin{tabular}{|c|c|c|c|c|c|c|}
\hline $\begin{array}{l}\text { Patient } \\
\text { No }\end{array}$ & $\begin{array}{l}\text { Age } \\
(y)\end{array}$ & $F E V_{1}$ & $V C$ & $T L C$ & $T L C O$ & KCO \\
\hline
\end{tabular}

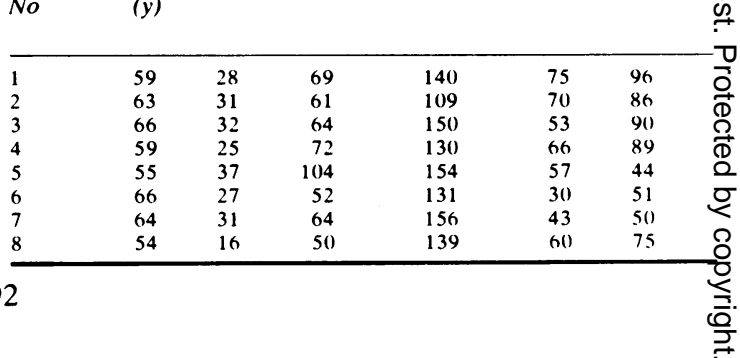


was allowed during this period.

Each patient was admitted to hospital two days before the study and spirometry was performed twice daily to ensure that there was no significant variability of airflow obstruction and two practice 12-minute walks were performed during this period. $^{5}$ On each of the subsequent five days each patient inhaled, under supervision, a lactose placebo or $200,400,800$, or $1600 \mu \mathrm{g}$ salbutamol powder from Rotacaps via the new-style Rotahaler (Allen and Hanburys). The doses were given in randomised, double-blind fashion and each dose was taken from four rotacaps which were identical in external appearance and inhaled in rapid succession. The drugs were administered at the same time each morning. $\mathrm{FEV}_{1}$ and vital capacity were measured with a Vitalograph bellows spirometer immediately before and at 15, 30 and 60 minutes and two, four and six hours after each dose. Maximum expiratory and inspiratory flow volume curves were obtained

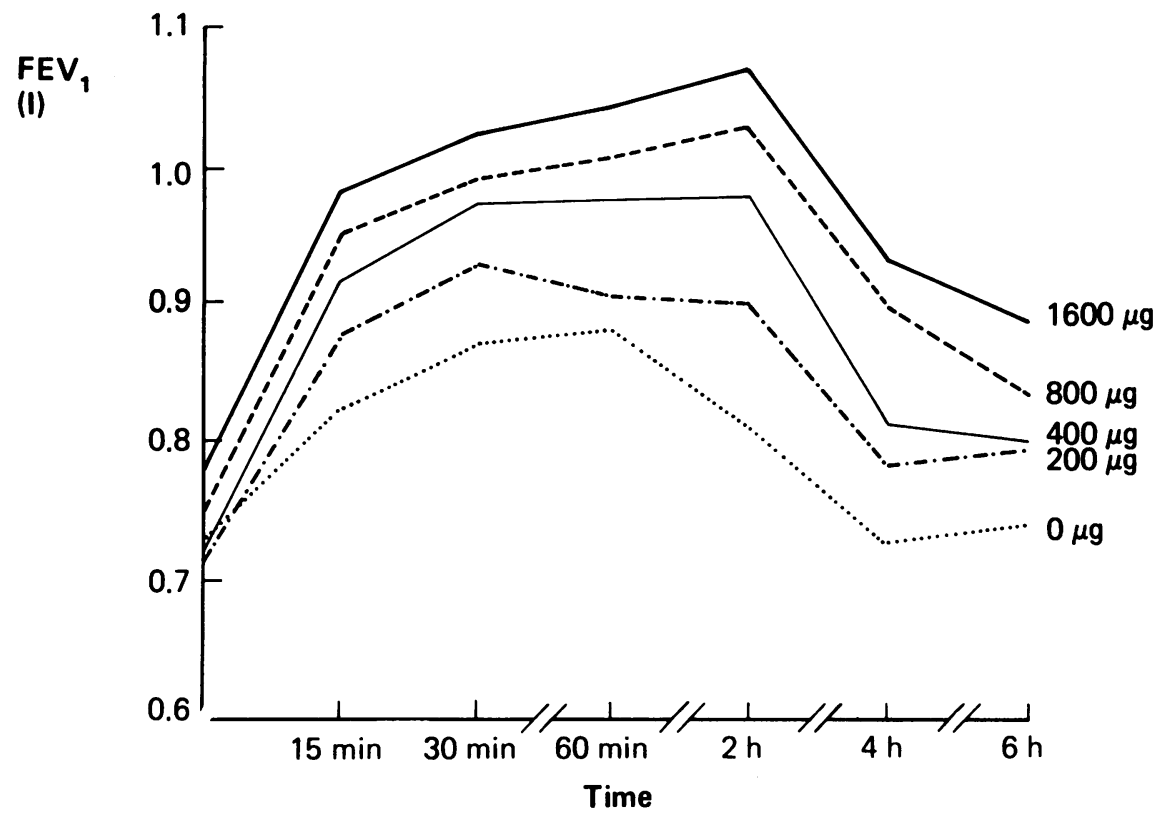

Fig 1 Mean values of $F E V_{1}$ for each dose of salbutamol at each time, showing a significant increase in overall FEV, with each increase in dose $(p<0.01)$.

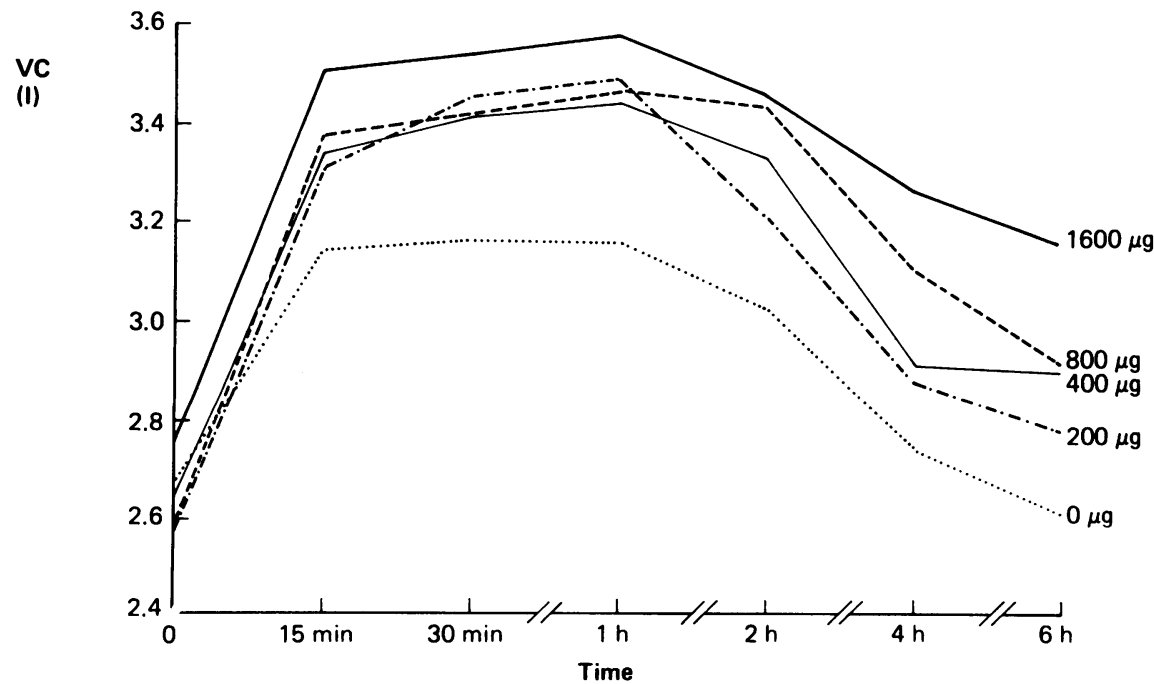

Fig 2 Mean values of vital capacity $(V C)$ for each dose at each time, showing a significant increase in overall VC with each increase in dose $(p<0.05)$ except between 200 and 400 $\mu \mathrm{g}$. 
with an Ohio Spirometer 15 minutes before and 15 minutes and one and four hours after each dose. Repeat flow-volume curves were obtained on each occasion until three reproducible curves were produced. The curves were displayed on a storage oscilloscope and photographed to allow measurement of peak inspiratory flow (PIF). The 12-minute walking distance (12-MD) was measured one hour before and one and four hours after the drug was inhaled.
For each index of response Newman Keul's method of analysis of variance ${ }^{8}$ was used to compare $\stackrel{9}{\stackrel{9}{+}}$ the overall effects of the different doses on the absolute values recorded over the whole period of measurement. In addition, dose-response curves were constructed for each index at the time of inhalation $\triangle$ and one, two, and four hours afterwards, and the significance of the differences between the effects of the different doses was assessed by paired $t$ tests.
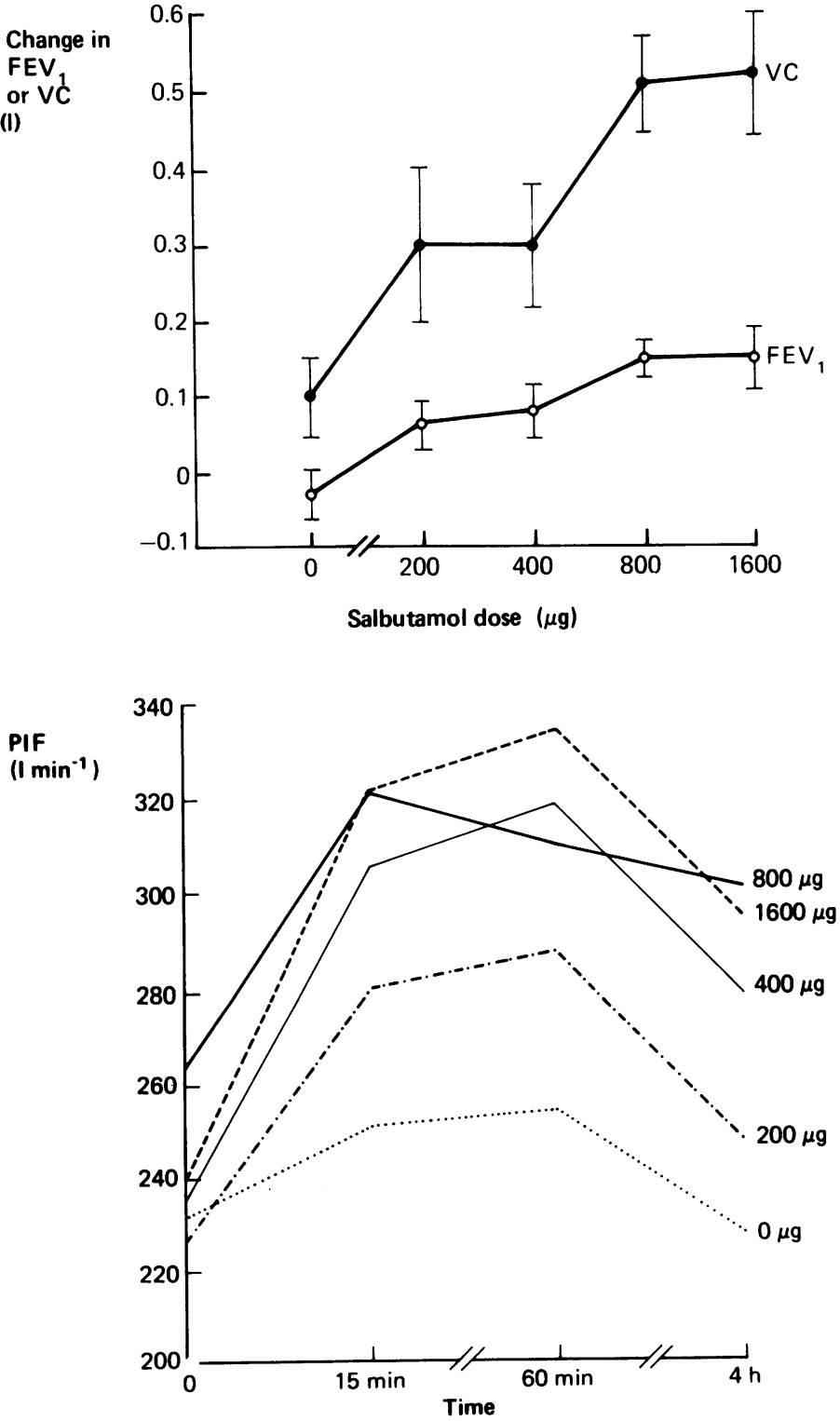

Fig 3 Salbutamol dose-response curve showing mean change in $F E V_{1}$ and $V C \pm$ SEM with each dose four hours after inhalation. The following differences were significant $(p<0.05)$ for both FEV and $V C:$ None $v$ all the doses; $200 v 800,1600$ $\mu \mathrm{g} ; 400 v 800,1600 \mu \mathrm{g}$.
Fig 4 Mean values of peak inspiratory flow (PIF) for each dose at each time, showing a significant increase in overall $P I F$ with each increase in dose $(p<0.05)$ except between 400 and $800 \mu \mathrm{g}$. 


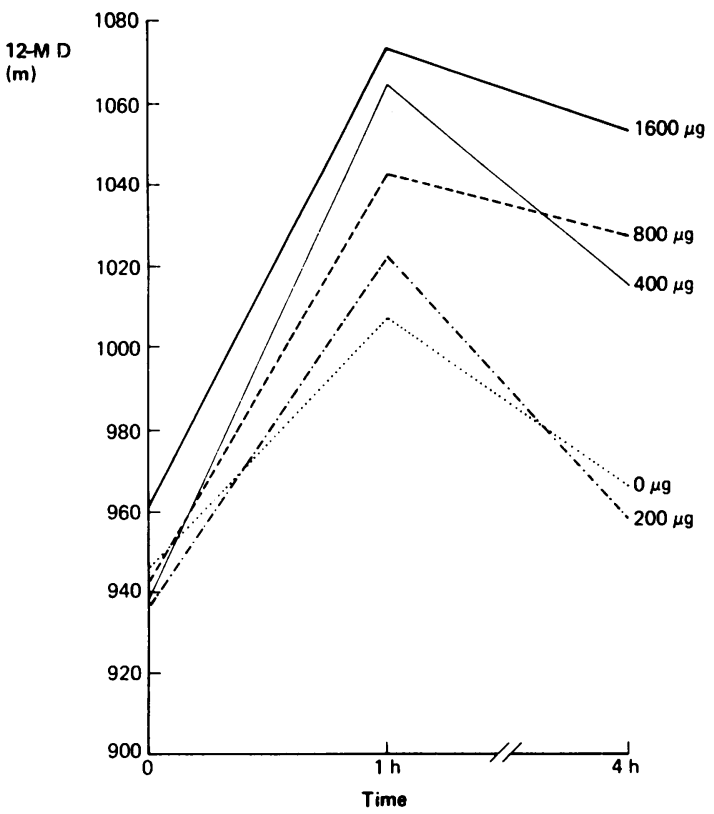

Fig 5 Mean values for 12-minute walking distance (12-MD) for each dose at each time, showing a significant increase with each increase in dose $(p<0.05)$ except between 0 and $200 \mu \mathrm{g}$ and between 400 and $800 \mu \mathrm{g}$.

\section{Results}

Figures 1 and 2 show the mean values of $\mathrm{FEV}_{1}$ and VC for each dose at each time. There were no significant differences between the preinhalation FEV , or VC values on different days. Analysis of variance showed that a greater $\mathrm{FEV}_{1}$ was achieved with each increase in dose $(p<0.01)$ and that a greater VC was obtained with each increase in dose except that from 200 to $400 \mu \mathrm{g}(\mathrm{p}<0.05)$. The larger doses appeared to have a longer duration of action and this was confirmed by the dose-response curves four hours after the drug had been inhaled (fig 3). All doses of active drug produced greater increases in FEV and VC than placebo. Both 1600 and $800 \mu \mathrm{g}$ were significantly better than 400 and $200 \mu \mathrm{g}$ at four hours but with earlier measurements the distinction was less clear.

Figures 4 and 5 show the PIF and 12-MD for each dose at each time. There were no significant differences between the preinhalation values on different days. The results were analysed as for FEV, and VC, but the gradations of response were less clearcut. Dose-response curves based on the PIF and 12-MD at four hours after drug inhalation are shown in figure 6 and these give information similar to the spirometric measurements.

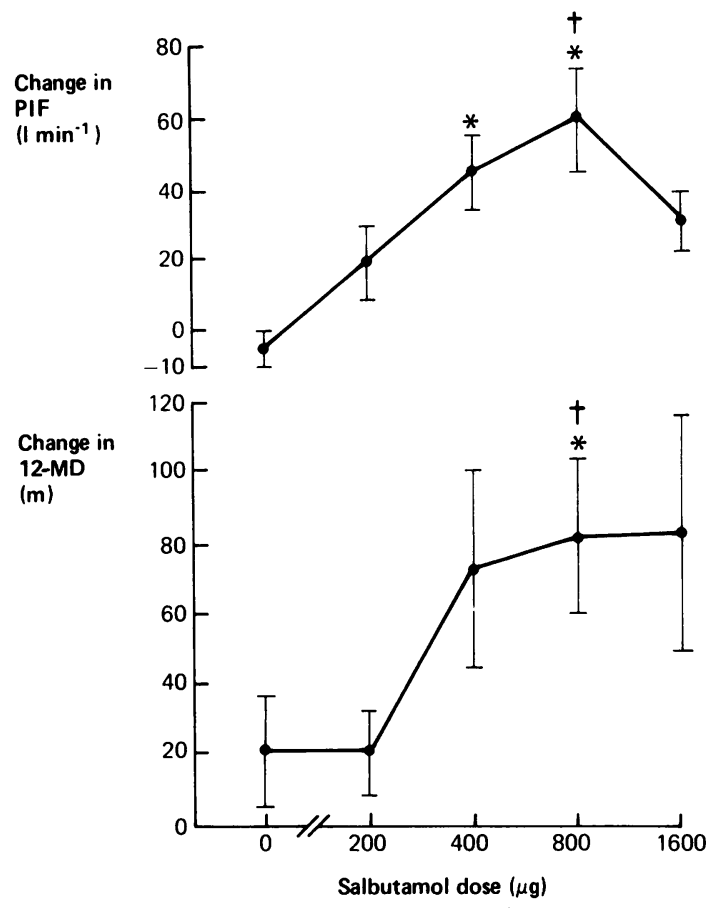

Fig 6 Salbutamol dose-response curve showing mean change in peak inspiratory flow (PIF) and 12-minute walking distance (12-MD) $\pm S E M$ with each dose four hours after inhalation. *Significantly greater than placebo $(p<0.05)$; †significantly greater than $200 \mu \mathrm{g}(p<0.05)$.

\section{Discussion}

A clear relationship between degree of bronchodilatation and dose of inhaled salbutamol has been shown previously in asthmatic patients. ${ }^{910}$ The present study has shown that a gradation of response is also seen in patients with chronic, largely irreversible, airflow obstruction. The longer the period after inhalation the clearer the dose effect became and the larger the dose the longer its duration of action. Prolongation of the effect of salbutamol with larger doses has previously been shown with a nebulised solution delivered by intermittent positive-pressure breathing to asthmatic patients. ${ }^{10}$

A large placebo response was observed in the present study and the explanation for this is not clear. All patients had previously used $\beta$-stimulants with clinical benefit and their expectations were probably high after a period of abstinence from regular use. The drugs were given in the morning and some improvement could be expected spontaneously at that time of day but the decline after two hours would not be expected if this were the complete explanation. 
Although one criterion for entry into the study was failure of the $\mathrm{FEV}_{1}$ to improve by $15 \% 15$ minutes after two puffs $(200 \mu \mathrm{g})$ of salbutamol from a conventional aerosol, the mean improvement in $\mathrm{FEV}_{1}$ observed during the study 15 minutes after $200 \mu \mathrm{g}$ salbutamol was $20 \%$ and after two hours $25 \%$. This paradox may be explained by the different mode of administration or possibly by tolerance to salbutamol at the initial testing, reversed by abstinence from the drug for 10 days before the study. The maximum bronchodilator effect was seen between one and two hours after inhalation for all doses, and it follows that when patients with chronic airflow obstruction are tested for maximal response to a long-acting inhaled $\beta$-stimulant at least one hour should elapse before spirometry is repeated.

It has been suggested that spirometric measurement alone may not be the most appropriate technique for assessing response to treatment in patients with airflow obstruction in view of the effects of dynamic airways compression on expiratory airflow. ${ }^{3}$ For this reason we also measured inspiratory flow-volume curves and the 12-minute walking distances. Of the various indices derived from the flow-volume curves, only the PIF data have been reported as the other measurements failed to provide further information. Assessment of response based on any one of the indices FEV, VC, PIF, and 12-MD produced similar conclusions but the most clearcut dose-response relationships were found with FEV, and with VC. In particular, the walking test appeared to offer no advantage in these patients and the measurement is time consuming and showed greater variation than the other tests (the mean within-subject coefficient of variation for 12-MD before drug inhalation on the five days of the study was $7.4 \%$, compared with 4.8 and $4.6 \%$ for $\mathrm{FEV}_{1}$ and VC). This study therefore supports the use of spirometric measurements of $\mathrm{FEV}_{1}$ and relaxed $\mathrm{VC}$ for assessment of the response to treatment in these patients despite the theoretical objections.

We conclude that there is a graded dose-response relationship to inhaled salbutamol powder in patients with chronic airflow obstruction and that

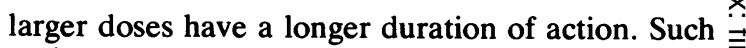
patients should not be dismissed as having "irrevers- $\stackrel{\vec{F}}{\rightarrow}$ ible" airflow obstruction as potentially helpful treatment may be withheld. On the basis of the measurements reported here, an inhaled dose of 800 $\mu \mathrm{g}$ dry powder gives optimal improvement, but $\stackrel{\Phi}{\stackrel{D}{\Omega}}$ whether regular use of such doses would produce sustained benefit is not known.

We wish to thank Mrs Y Ferguson for technical $\vec{\omega}$ assistance and Dr LA Phillips and Allen and Hanburys Ltd for providing the Rotahalers and cap- $\bar{x}$ sules.

\section{References}

1 Choo-Kang YFJ Grant IWB Comparison of two methods of administering bronchodilator aerosol to asthmatic patients. Br Med J 1975;ii:119-20.

${ }^{2}$ Cayton RM, Webber B, Patterson JW, Clark TJH. A comparison of salbutamol given by pressure-packed aerosol or nebulisation via IPPB in acute asthma. Br J Dis Chest 1978;72:222-4.

${ }^{3}$ Ramsdell JW, Tisi GM. Determination of bronchodilation in the clinical pulmonary function laboratory. Role of changes in static lung volumes. Chest 1979; 76:622-8.

${ }^{4}$ Bellamy D, Hutchinson DCS. The effects of salbutamol aerosol on lung function in patients with pulmonary emphysema. Br J Dis Chest 1981;75:190-6.

${ }^{5}$ McGavin CR, Gupta SP, McHardy GJR. Twelve minute $\overline{\bar{O}}$ walking test for assessing disability in chronic 3 bronchitis. Br Med J 1976;i:822-3.

- Conellan SJ, Gough SE. The effects of nebulised salbutamol on lung function and exercise tolerance in patients with severe airflow obstruction. $\mathrm{Br} J \mathrm{Dis}$ Chest 1982;76:135-42.

${ }^{7}$ Holgate ST, Baldwin CJ, Tattersfield AE. $\beta$-agonist resistance in normal human airways. Lancet 1977; ii:375-7.

${ }^{8}$ Armitage P. Statistical methods in medical research. $\delta$ Oxford: Blackwell Scientific Publications, 1971;7.3, $8 \cdot 1$.

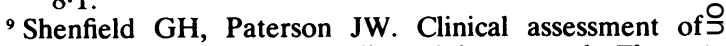
bronchodilator drugs delivered by aerosol. Thorax 1973;28:124-8.

${ }^{10}$ Ruffin RE, Obminski G, Newhouse MT. Aerosol salbutamol administration by IPPB: lowest effective S dose. Thorax 1978;33:689-93. 